Ann. Geophysicae 14, 1454-1461 (1996) C EGS - Springer-Verlag 1996

\title{
Radar observations of ionospheric irregularities at Syowa Station, Antarctica: a brief overview
}

\author{
T. Ogawa \\ Solar-Terrestrial Environment Laboratory, Nagoya University, 3-13 Honohara, Toyokawa, Aichi 442, Japan
}

Received: 22 January 1996/Revised: 12 April 1996/Accepted: 15 May 1996

\begin{abstract}
We briefly overview the radar observations that have been made for 30 years at Syowa Station, Antarctica for studying small-scale electron-density irregularities in the southern high-latitude $E$ - and $F$-region ionosphere. Some observational results (i.e., long-term variations of radio aurora, Doppler spectra with narrow spectral widths and low Doppler velocities, and simultaneous observations of radar and optical auroras) from VHF radars capable of detecting 1.3- to 3-m scale irregularities are presented. A new $50-\mathrm{MHz}$ radar system equipped with phased-antenna arrays began operation in February 1995 to observe two-dimensional behaviors of $E$-region irregularities. An HF radar experiment also began in February 1995 to explore decameter-scale $E$ - and $F$-region irregularities in the auroral zone and polar cap. These two radars will contribute to a better understanding of the ionospheric irregularities and ionospheric physics at southern high latitudes.
\end{abstract}

\section{Introduction}

HF-VHF radar studies of ionospheric irregularities at high latitudes have been extensively carried out in the Arctic (Fejer and Kelley, 1980; Haldoupis, 1989; Greenwald et al., 1995). On the contrary, such studies in the Antarctic have been scarce: VHF and HF radars at Syowa Station since 1966, VHF radar at Siple Station from 1976 to 1978 (e.g., Ogawa et al., 1982), and HF radar at Halley Bay since 1988 (Greenwald et al., 1995). The radar measurements at a Japanese Antarctic station, Syowa Station (geographic coordinates, $69.00^{\circ} \mathrm{S}, 39.58^{\circ} \mathrm{E}$; magnetic coordinates, $66.12^{\circ} \mathrm{S}, 70.71^{\circ} \mathrm{E} ; L=6.10$ ) started in 1966 as part of routine ionospheric observations. Since then, we have mainly used $50-\mathrm{MHz}$ radars to explore the $E$-region irregularities and studied the following subjects: (1) long-term variations of radio-aurora activity (Ohtaka and Tanaka, 1993), (2) relations among echo intensity, Doppler velocity, and spectral width (Ogawa and
Igarashi, 1982), (3) Doppler spectra with both narrow spectral widths and low Doppler velocities (Tanaka et al., 1990; Kunitake et al., 1993), (4) Pc-5 geomagnetic pulsations (Igarashi et al., 1985), and (5) simultaneous observations of radar aurora and optical aurora with a ground-based photometer (Igarashi and Tsuzurahara, 1981; Ogawa et al., 1989a) and with sounding rockets (Igarashi et al., 1981). The 50-MHz radar was occasionally used as a meteor radar to detect neutral winds and gravity waves at altitudes between 80 and $100 \mathrm{~km}$ (e.g., Ogawa et al., 1989c). In this paper, we briefly overview the results relating to items (1), (3), and (5), and then describe new VHF and HF radar experiments that started operation in February 1995.

Most of the scientific results from the Syowa Station radar observations have appeared in both Memoirs of National Institute of Polar Research and Proceedings of the NIPR Symposium on Upper Atmosphere Physics published by the National Institute of polar Research, Japan. The main objective of this paper is to introduce our research activities to readers who are unfamiliar with these Japanese journals.

\section{VHF radar observations}

\subsection{Radars}

The first radar experiment at Syowa Station was carried out in 1966 with a 112-MHz PPI (plan position indication) radar to monitor radio-aurora occurrences in a horizontal plane (Hasegawa and Shiro, 1970). This radar was replaced in 1974 by a radar using four frequencies $(50,65$, 80 , and $112 \mathrm{MHz}$ ) and eight-element Yagi antennas to investigate a frequency dependence of radar-echo intensity. This second radar was modified in 1978 to observe Doppler spectra of 50-MHz radar echoes (Igarashi et al., 1981). Then a VHF coherent radar system transmitting two frequencies (50 and $112 \mathrm{MHz}$ ) in two fixed directions began operation in 1982 (Igarashi et al., 1982). This radar had almost continuously observed Doppler spectra and 


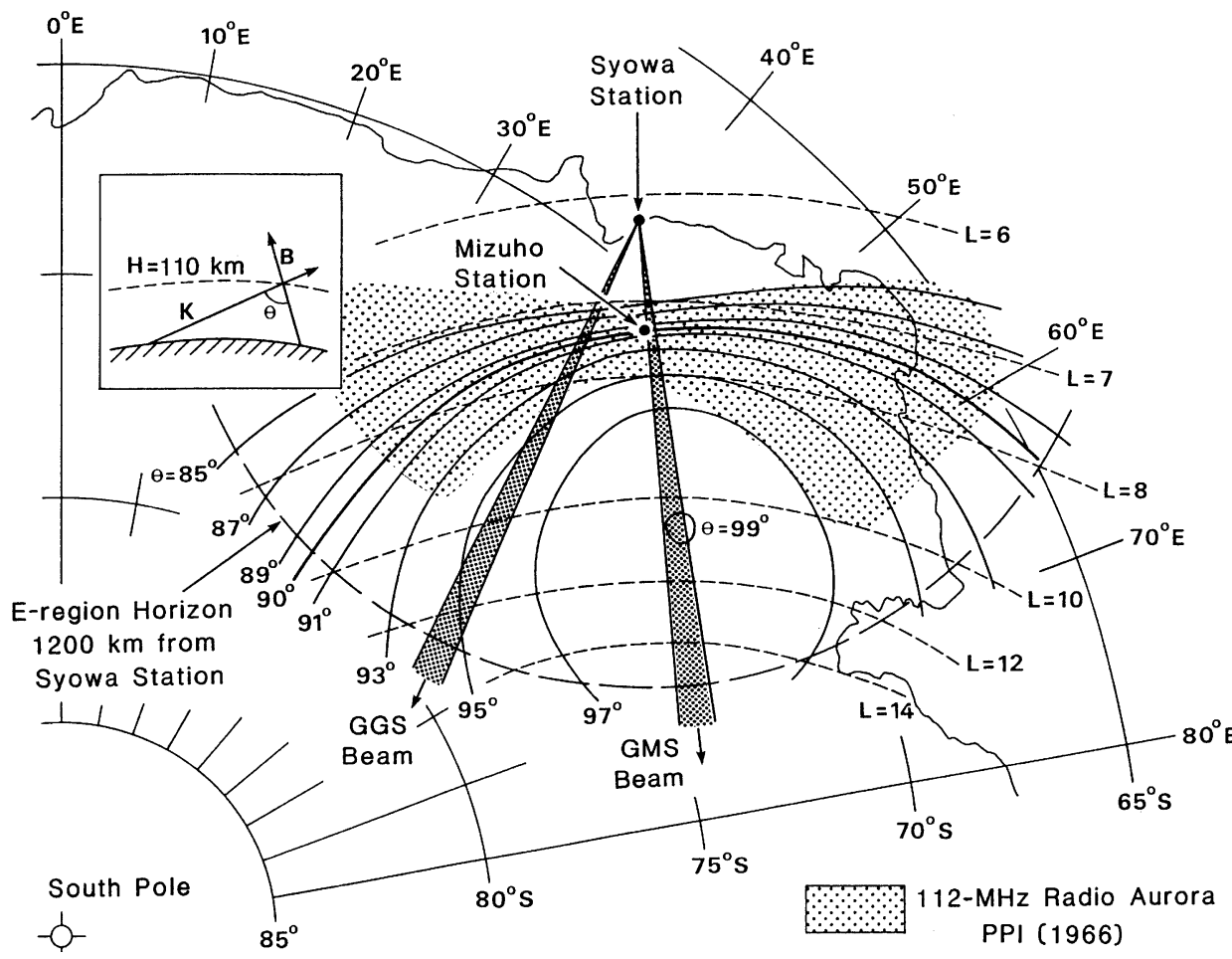

Fig. 1. Plan view of two radar antenna-beam patterns together with contours of $L$ value and aspect angle $\theta$; $\theta$ is defined in the figure. The azimuth measured from geographic north to east is $135.0^{\circ}$ for the GMS beam and $166.4^{\circ}$ for the GGS beam. The dotted area represents the region of $112-\mathrm{MHz}$ radio auroras recorded by PPI in 1966 (from Igarashi et al., 1982) intensities of 50- and $112-\mathrm{MHz}$ echoes until the end of 1994.

As shown in Fig. 1, the radar used for the period 1982-1994 had two antenna beams, one toward geomagnetic south (GMS beam) and the other toward approximately geographic south (GGS beam), with a crossing angle of $31.4^{\circ}$ to investigate two-dimensional structures of the $E$-region irregularities. Each beam had a beam width of approximately $4^{\circ}$ in the horizontal plane and was formed by using three 14-element coaxial collinear antennas. Figure 1 also illustrates the magnetic $L$-shell and aspect angle ( $\theta$ defined in the figure) contours together with the echo area measured by the $112-\mathrm{MHz}$ PPI radar in 1966. It is recognized that the $112-\mathrm{MHz}$ echoes return only from the region having $\theta$ between $85^{\circ}$ and $95^{\circ}$ (aspect-sensitivity characteristics). The aspect sensitivity limited the $50-\mathrm{MHz}$ echo ranges to $240-360$ and $240-405 \mathrm{~km}$ for the GMS and GGS beams, respectively. These beam coverages were extremely narrow compared with, for example, the coverages provided by the Siple Station 50MHz radar (Ogawa et al., 1982).

\subsection{Some results}

Figure 2 shows long-term variations of the radar-echo occurrences from 1978 to 1990 (Ohtaka and Tanaka, 1993). To depict this figure, the $50-\mathrm{MHz}$ radar data were analyzed for the periods from 1978 to 1986 and from 1989 to 1990 , while the $112-\mathrm{MHz}$ data were used in 1987 and 1988 because of repairs to the $50-\mathrm{MHz}$ radar. As shown in Fig. 2a, the diurnal variation exhibits a maximum occurrence after local midnight $(\mathrm{UT} \simeq \mathrm{MLT} \simeq \mathrm{LT}-3 \mathrm{~h})$ and a minimum occurrence around noon (1000-1100 UT). Such a diurnal variation is quite reasonable (e.g., Waldock et al., 1985) due to the fact that auroral electrojets capable of exciting $E$-region irregularities are closest to the radar field of view around midnight and farthest from it around noon. The monthly averaged occurrence rates in Fig. $2 b$ and c exhibit semiannual variations with minima in summer (December) and winter (June). For the postmidnight echoes (Fig. 2c), the summer minima are more enhanced than the winter minima. For the solar cycle variation, there exist two occurrence peaks: a major peak in the declining phase of the sunspot number (1983 and 1984) and a secondary peak in the increasing phase (1989). These semiannual and solar cycle variations of the radar echoes are consistent with the well-known semiannual and solar cycle variations of geomagnetic activity (Russell and McPherron, 1973; Gorney, 1990; Ohtaka and Tanaka, 1993). Such a correlation is expected, since electric fields in the polar ionosphere, essentially important for exciting the two-stream and gradient-drift irregularities, are largely dependent on geomagnetic activity level. The seasonal and solar cycle variations of the echo occurrences for 13 years (1978-1990) are nearly consistent with those for 6 years (1958-1963) in the northern hemisphere (Hultqvist and Egeland, 1964). Our long-term data set may be useful for studying the solar wind/magnetosphere interaction process.

The generation process of radar auroras is completely different from that of visible auroras. Radar auroras are caused by electron-density irregularities due to electric-field and/or electron-density gradient, whereas visible auroras in the $E$ region are produced by energetic electrons of a few to $10 \mathrm{keV}$ coming from the magnetosphere. 

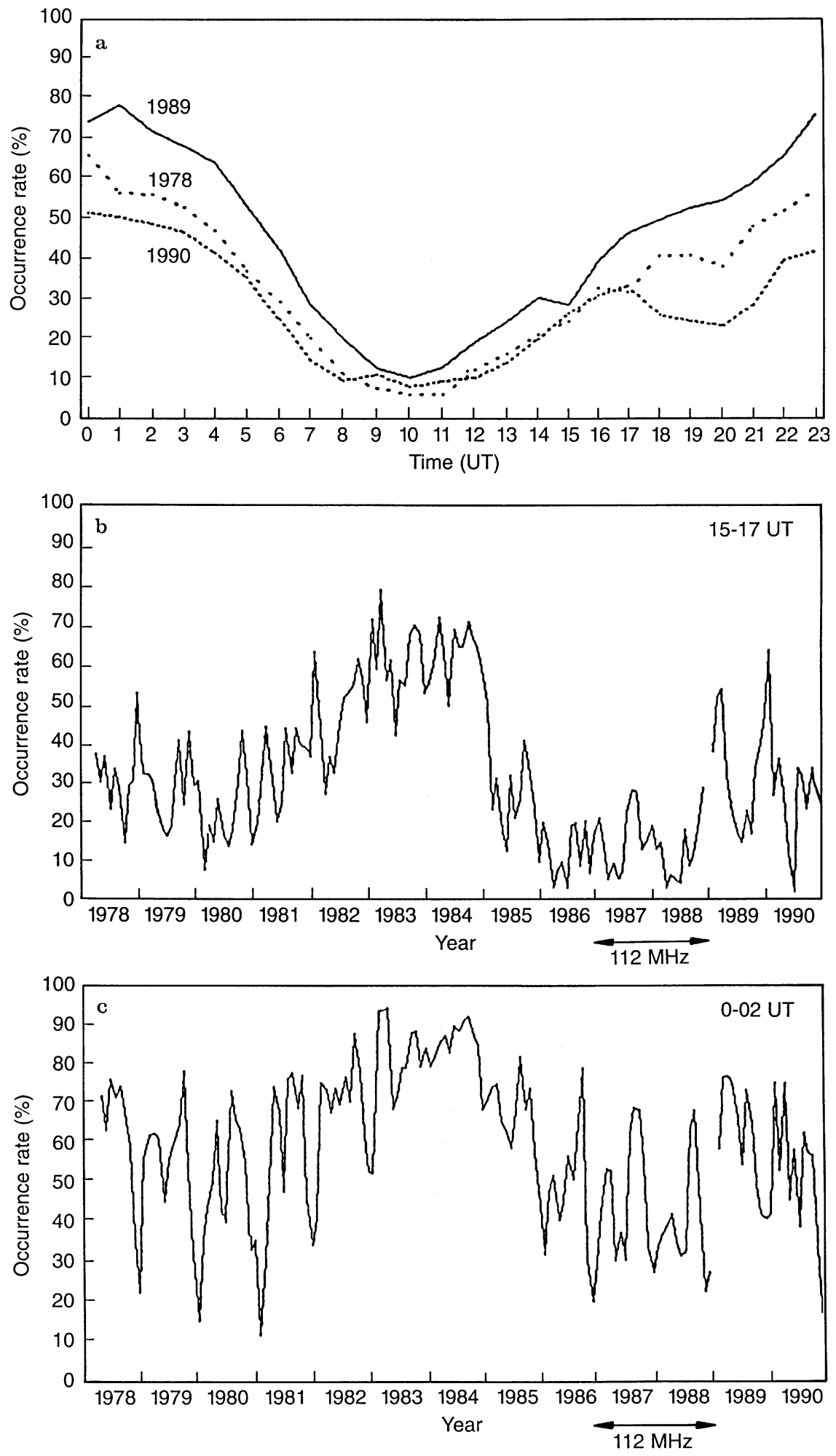

Fig. 2a-c. Long-term variations of $50-\mathrm{MHz}$ (112-MHz in part) radar-echo occurrences. a Diurnal variations for 1978,1989 , and 1990. b Monthly averaged variation for 1500-1700 UT. c Monthly averaged variation for 0000-0200 UT (from Ohtaka and Tanaka, 1993)
Therefore simultaneous observations of radar and visible auroras in a common volume are important for understanding the electrodynamics of aurora (e.g., Lewis et al., 1994). Igarashi and Tsuzurahara (1981) examined a correlation between radar-echo intensity and visible-aurora luminosity over Mizuho Station (see Fig. 1: geographic coordinates, $70.70^{\circ} \mathrm{S}, 44.33^{\circ} \mathrm{E}$; magnetic coordinates, $\left.67.98^{\circ} \mathrm{S}, 70.96^{\circ} \mathrm{E}\right), 270 \mathrm{~km}$ geomagnetic south of Syowa Station. The area, $100 \mathrm{~km}(\mathrm{~N}-\mathrm{S}$ direction $) \times 200 \mathrm{~km}$ (E-W direction), probed by the Syowa Station $50-\mathrm{MHz}$ radar, however, was very much wider than the area $(10 \mathrm{~km} \times 10 \mathrm{~km})$ viewed by a $4278-\mathrm{A}$ photometer at 
Mizuho Station. Ogawa et al. (1989a) made similar experiments in 1985 in a much smaller common area, $15 \mathrm{~km}$ $(\mathrm{N}-\mathrm{S}$ direction $) \times 20 \mathrm{~km}(\mathrm{E}-\mathrm{W}$ direction $)$. In this case radar aurora was observed by using the GMS beam of the $50-\mathrm{MHz}$ radar with a range resolution of $15 \mathrm{~km}$ (see Fig. 1), while visible aurora was monitored by a 4278-A zenith photometer with a view angle of about $7^{\circ}$ at Mizuho Station. A moderate substorm occurred before the midnight of 5 October 1985. Figure 3 shows time variations of the geomagnetic $H$ component at Mizuho, the 4278-A intensity over Mizuho, and the radar-echo intensity at a slant range of $285 \mathrm{~km}$ from Syowa Station. In association with a large depression of the $H$ component during 1940-1951 UT, both the auroral and radar-echo intensities were often enhanced with a very clear anticorrelation between them. These auroras can be regarded as multiple arcs that traversed successively the field of view of the Mizuho photometer. From an examination of the Doppler spectra taken by the radar, we found that the strong radar echoes that appeared between the bright arcs were caused by the gradient-drift plasma instability, while the electric fields were suppressed within the arcs. Radar echoes due to the two-stream plasma instability driven by electric fields exceeding $25 \mathrm{mV} \mathrm{m}^{-1}$ were detected within

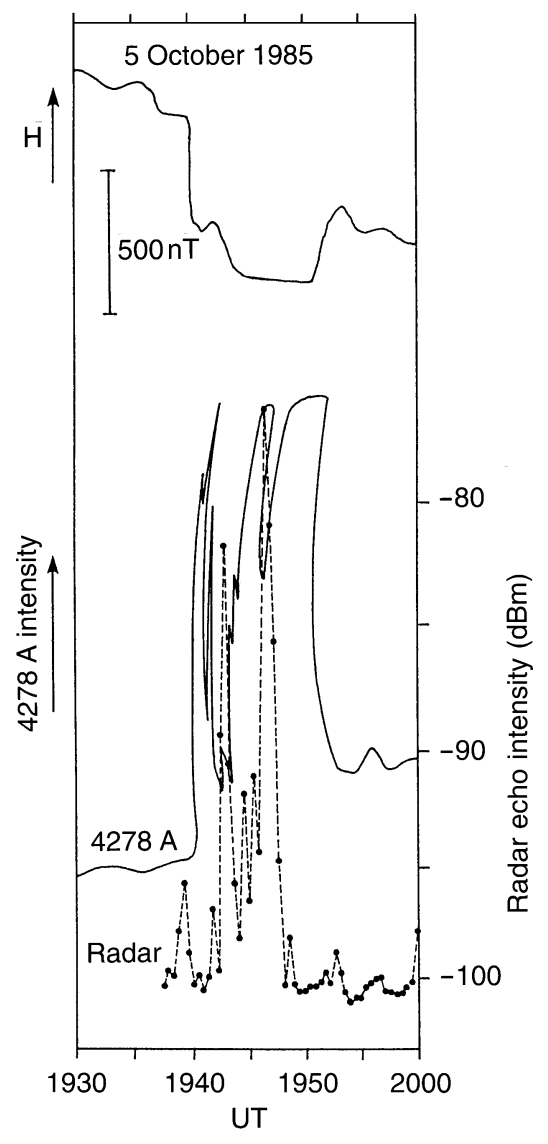

Fig. 3. Time variations of geomagnetic $H$ component at Mizuho, 4278-A auroral intensity over Mizuho, and 50-MHz radar echo intensity at a range of $285 \mathrm{~km}$ on GMS beam from Syowa on 5 October 1985 . Note the saturation of auroral intensity around 1946 and 1950 UT (from Ogawa et al., 1989a) faint, diffuse-like auroras that followed the bright arcs shown in Fig. 3.

Auroral radar echoes observed in the $E$ region can be classified into four types (e.g., Haldoupis, 1989). Type-1 and -2 echoes are very popular ones and are believed to be generated by the two-stream and gradient-drift instabilities, respectively. Type-3 echoes appearing under geomagnetically disturbed conditions have very narrow spectra peaked below ion acoustic velocities: Doppler frequency shifts are between $20 \mathrm{~Hz}\left(60 \mathrm{~m} \mathrm{~s}^{-1}\right)$ and $70 \mathrm{~Hz}\left(210 \mathrm{~m} \mathrm{~s}^{-1}\right)$ when $50-\mathrm{MHz}$ radars are used. These frequency shifts are seemingly close to the cyclotron frequencies, or their harmonics, of the main ion species in the $E$ region (i.e., $\mathrm{O}_{2}^{+}$, $\mathrm{NO}^{+}, \mathrm{O}^{+}$). Haldoupis (1989) notes that all the type-3 observations were made with high-resolution $50-\mathrm{MHz}$ radars whose beam directions were several degrees from perpendicularity with the geomagnetic field. Many researchers tried to relate type- 3 echoes to electrostatic ion cyclotron (EIC) waves, but this interpretation has been ruled out (e.g., Watermann, 1994). The excitation mechanism of type-3 echoes is still unknown. A sounding rocket that was launched at Syowa Station in 1978 detected ion cyclotron waves at altitudes of $200 \mathrm{~km}$ (Ogawa et al., 1981). Type-4 echo spectra consisting of many short-lived narrow spectral peaks at high Doppler frequencies are observed during highly disturbed conditions (Haldoupis, 1989).

Figure 4 shows the Doppler spectra observed at three ranges, $240\left(\theta=86^{\circ}\right), 255\left(\theta=87^{\circ}\right)$, and $285 \mathrm{~km}\left(\theta=90^{\circ}\right)$, on the GMS beam in Fig. 1 (Tanaka et al., 1990). A severe magnetic disturbance started at 0415 UT on 5 September 1984, after which narrow spectral peaks with Doppler frequencies of about $12 \mathrm{~Hz}\left(36 \mathrm{~m} \mathrm{~s}^{-1}\right)$ appeared most clearly at a range of $240 \mathrm{~km}$. These frequencies are about the half of the cyclotron frequencies of $\mathrm{O}_{2}^{+}$and $\mathrm{NO}^{+}$ $(\sim 20 \mathrm{~Hz})$ and are less than the frequencies observed by other $50-\mathrm{MHz}$ radars in the northern hemisphere. Type-2 echoes are most dominant at $285 \mathrm{~km}$, where the geomagnetic aspect angle is close to $90^{\circ}$, whereas with decreasing aspect angle the type- 2 echoes die out and narrow spectral peaks with low Doppler frequencies become dominant. Tanaka et al. (1990) found that such particular echoes were distinctly detected on the GMS beam during postmidnight hours under disturbed conditions for 83 days from 25 April to 8 October 1984 . With increasing radar range the aspect angle for the GMS beam changes more rapidly than that for the GGS beam (see Fig. 1). Such a beam configuration may be related to the fact that the GGS beam did not detect the particular echoes. Kunitake et al. (1993) who followed the work of Tanaka et al. (1990) reported a statistical result of the echoes having narrow spectral peaks with Doppler shifts of less than $\pm 20 \mathrm{~Hz}$. They found that these echoes have a maximum occurrence in the morning (5-6h UT), durations from a few tens of seconds to a few tens of minutes, and preferred ranges from 225 to $240 \mathrm{~km}\left(\theta=84^{\circ}-86^{\circ}\right)$ on the GMS beam and from 225 to $285 \mathrm{~km}\left(\theta=80^{\circ}-86^{\circ}\right)$ on the GGS beam. St.Maurice et al. (1994) have proposed that electron-density gradients with scale lengths as small as $100 \mathrm{~m}$ are the origin of narrow spectra with markedly low Doppler shifts. This process may be applicable to the Doppler 
Doppler spectrum -166 +166 Hz $\left(-500 \sim+500 \mathrm{~ms}^{-1}\right)$

5 September 1984
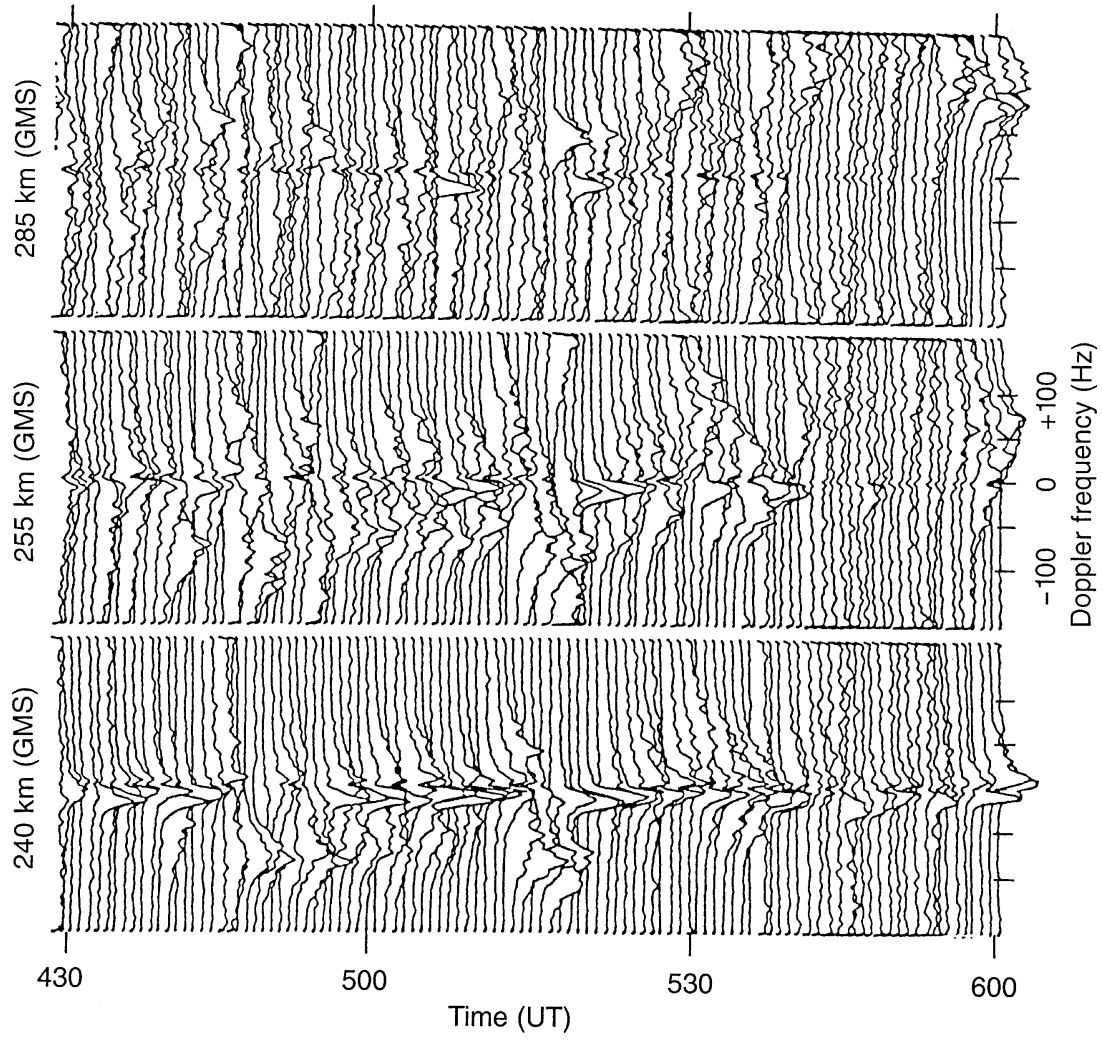

Fig. 4. Time variations of Doppler frequency spectra observed at ranges of 240,255 , and $285 \mathrm{~km}$ on GMS beam of $50-\mathrm{MHz}$ Syowa radar on 5 September 1984. Geomagnetic aspect angles at an altitude of $110 \mathrm{~km}$ at ranges of 240,255 , and $285 \mathrm{~km}$ are $86^{\circ}, 87^{\circ}$, and $90^{\circ}$, respectively. Full scale for the frequency axis ranges from -166 to $+166 \mathrm{~Hz}$, corresponding to Doppler velocity from -500 to $+500 \mathrm{~m} \mathrm{~s}^{-1}$ (from Tanaka et al., 1990)
Table 1. Parameters of scanning-beam 50-MHz radar (from Igarashi et al., 1995)

\begin{tabular}{ll}
\hline Frequency & $50.0 \mathrm{MHz}$ \\
Transmission: & \\
Peak power & $20 \mathrm{~kW}$ \\
Pulse width & $10-190 \mu \mathrm{s}(10-\mu$ s step) \\
PRF & $5-1275 \mathrm{~Hz}(5-\mathrm{Hz}$ step) \\
Pulse pattern & Single pulse, double pulse, multipulse \\
Antenna & Five 8-element Yagi antennas \\
Beam width & $\sim 30^{\circ}$ in azimuth \\
Beam coverage & $\pm 80^{\circ}$ in azimuth \\
Reception: & \\
Antenna (two sets) & Array of sixteen 3-element Yagi antennas \\
Beam width & $\sim 5^{\circ}$ in azimuth \\
Beam coverage & $\pm 80^{\circ}$ in azimuth \\
\hline
\end{tabular}

spectra reported by Tanaka et al. (1990) and Kunitake et al. (1993). More discussions are beyond the scope of this paper.

\section{$2.3 \mathrm{New}$ 50-MHz radar experiment}

A scanning-beam 50-MHz Doppler radar capable of observing a much wider area was installed in February 1995 at Syowa Station (Igarashi et al., 1995). Table 1 lists some

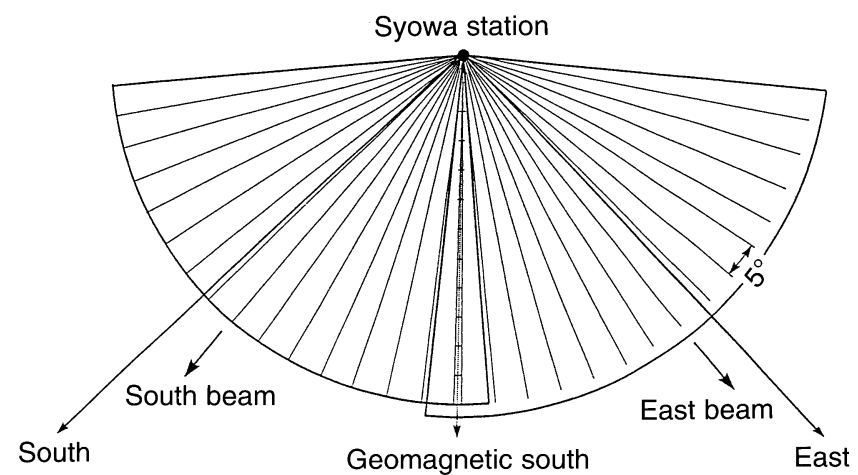

Fig. 5. Azimuthal coverage by two sets (east and west beams) of scanning-beam, receiving antenna array. Each antenna array has a beam width of about $5^{\circ}$

radar parameters. Five transmitting antennas, each having an azimuthal beam width of about $30^{\circ}$, cover a wide area of about $160^{\circ}$ in azimuth. As shown in Fig. 5, two sets of the phased-antenna array for reception provides a spatial coverage of about $160^{\circ}$ in azimuth with a resolution of about $5^{\circ}$. Note that the spatial coverage provided by the antenna arrays includes the whole $112-\mathrm{MHz}$ echo region shown in Fig. 1. Preliminary data indicate that the radar can detect $E$-region echoes at ranges between 240 and $1000 \mathrm{~km}$. Detailed data analysis will start in April 1996. 


\section{HF radar experiment}

The VHF radars can detect the $E$-region irregularities only in the auroral zone and are not applicable to the cleft

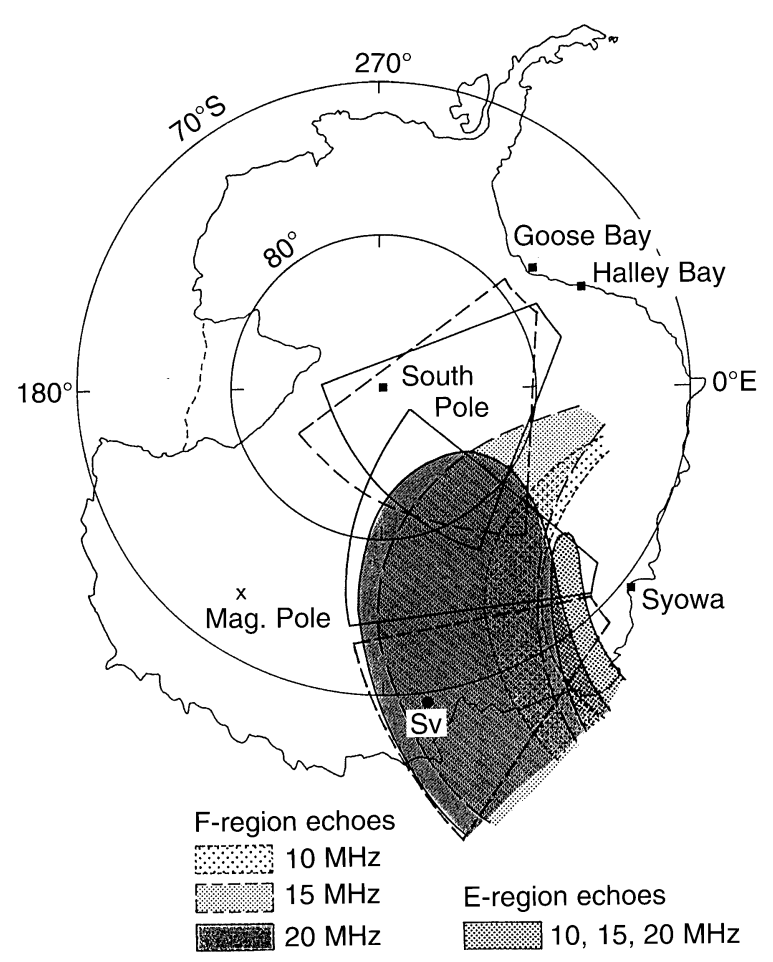

Fig. 6. $E$ - and $F$-region echo areas for three radar wave frequencies $(10,15$, and $20 \mathrm{MHz})$ seen from the Syowa Station HF radar. Fields of view of the Syowa Station and Halley Bay radars are indicated by a solid wedge. Fields of view of the second Syowa Station and Goose Bay HF radars are shown by a broken wedge. Note that the actual fields of view of the HF radars extend to a much larger distance (up to $3000 \mathrm{~km})$ than that shown on the figure $(2000 \mathrm{~km})$. "Sv" marks a geomagnetically conjugate point of the Svalbard incoherent scatter radar site (from Ogawa et al., 1990) and polar-cap regions far poleward of Syowa Station. To overcome this limitation, we proposed to construct an HF radar capable of detecting $E$ - and $F$-region echoes from ranges between 300 and a few thousand kilometers (Ogawa et al., 1989b, 1990). The usefulness of an HF radar for studying plasma convection in the polar cap, cleft, and auroral regions, traveling ionospheric disturbances, and irregularity production and dissipation mechanisms has been demonstrated by the HF radars at Goose Bay in Canada and Halley Bay in Antarctica $\left(75.52^{\circ} \mathrm{S}, 26.60^{\circ} \mathrm{W}\right)$ established in 1983 and 1988, respectively, and other radars (Greenwald et al., 1995, and references therein).

The Syowa Station HF radar, which is almost identical to the Goose bay HF radar (Greenwald et al., 1985), was constructed by the National Institute of Polar Research (NIPR) and began operation in February 1995 to observe a wide area in the ionosphere over the Antarctic Continent. More importantly, this radar contributes to the SuperDARN Project (Greenwald et al., 1995) and constitutes a twin radar system with the Halley Bay HF radar, which enables us to determine horizontal flow patterns of the ionospheric plasma. Figure 6 shows the echo area that can be covered by the Syowa Station HF radar (Ogawa et al., 1990). In calculating this area, we assumed a Chapman-type ionospheric electron density distribution with a maximum density of $3 \times 10^{5} \mathrm{~cm}^{-3}$ at $250 \mathrm{~km}$ and a scale height of $50 \mathrm{~km}$. The radar field of view (about $50^{\circ}$ in azimuth and $2000 \mathrm{~km}$ in range) is indicated by the solidwedge pattern. Also shown in Fig. 6 is the field of view of the Halley Bay radar. A horizontal plasma flow can be derived for the overlapping fields of view from the Halley Bay and Syowa Station radars. The overlapping area will also be probed with the third Antarctic HF radar that will begin operation at Sanae Station $\left(71.67^{\circ} \mathrm{S}, 2.85^{\circ} \mathrm{W}\right)$ in early 1996 (Greenwald et al., 1995).

An example of data from the Syowa Station radar is displayed in Fig. 7, where there are two echo regions, the $E$-region echoes at ranges less than $500 \mathrm{~km}$ and the

\section{SYOWA RANGE-TIME-PARAMETER PLOT: BEAM: 15}

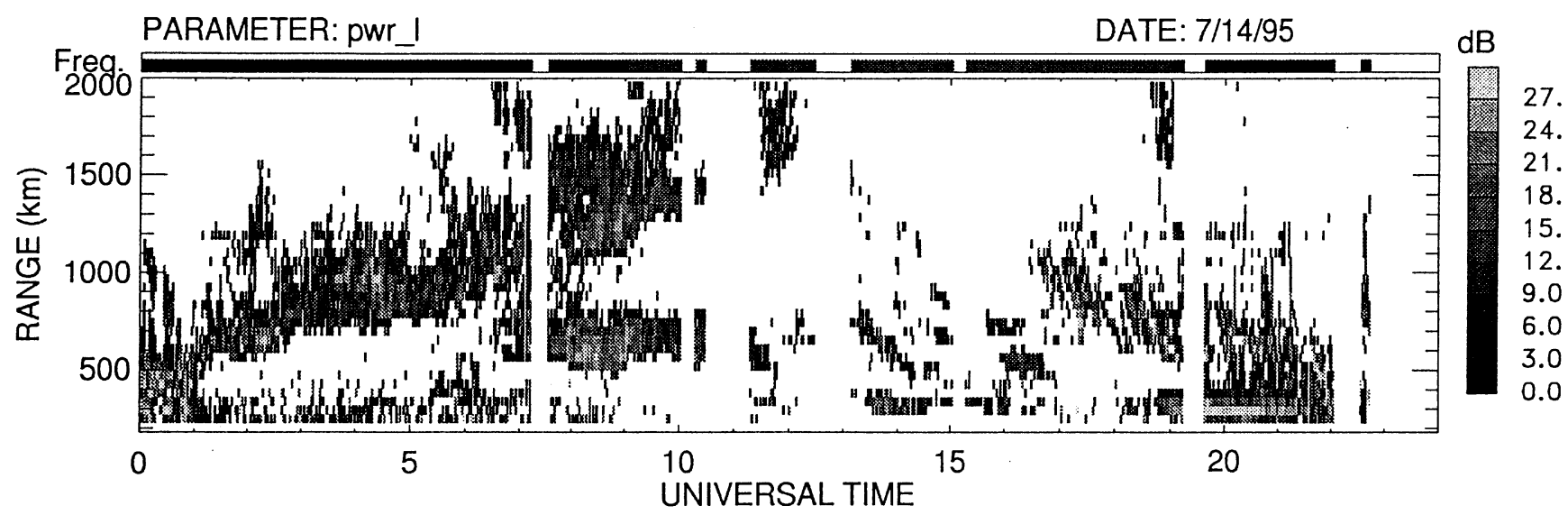

Fig. 7. Range-time-intensity plot of echo power observed on beam number 15 of Syowa Station HF radar on 14 July 1995. Beam 15 is directed toward the south magnetic pole (see Fig. 6). Radar frequen- cies used are between 12 and $13 \mathrm{MHz}$ during 0900-1900 UT and 9-10 MHz at other times. Echoes at ranges between 1500 and 2000 $\mathrm{km}$ during 0630-1200 UT are due to ground scatter 
$F$-region echoes at ranges beyond $500 \mathrm{~km}$. The $F$-regionecho ranges are closest to Syowa Station around midnight and farthest from it around noon. Equatorwardpropagating, quasi-periodic enhancements of the echo power are recognized between 1300 and 2200 UT, may be being a signature of medium-scale traveling ionospheric disturbances (e.g., Bristow et al., 1994) or of plasma structures recurrently coming to Syowa Station. More detailed analysis of the data is beyond the scope of this paper.

Another HF radar will begin operation at Syowa Station in early 1997. This radar can observe the new area (the broken-wedge pattern in Fig. 6) on the east of the area being probed with the existing HF radar and cover the geomagnetically conjugate point of the Svalbard (Spitsbergen) incoherent-scatter radar site. The $E$-region echo area in Fig. 6 is also being explored by the new scanning-beam $50-\mathrm{MHz}$ radar. It is very interesting to observe $E$-region irregularities simultaneously with the $\mathrm{HF}$ and VHF radars. We can also observe irregularities on the same geomagnetic field line simultaneously with both radars: $E$-region irregularities by the VHF radar and $F$-region irregularities by the HF radars. This enables us to study the electrical coupling between the $E$ and $F$ regions. To make such studies possible, we must know accurately points where HF and VHF radar waves are backscattered. In reality, this task may not be easy because of possible ionospheric refraction of radar waves (e.g., Uspensky et al., 1994).

An ionospheric volume illuminated by the Antarctic twin radars is geomagnetically connected with that over Greenland which is explored by the twin HF radars at Goose Bay in Canada and Stokkseyri in Iceland. The Goose Bay radar field of view mapped onto the Antarctica is shown in Fig. 6 by the broken wedge. Conjugate observations of plasma convection and irregularities are quite important for understanding similarities and dissimilarities of the phenomena between both hemispheres and for diagnostics of the magnetosphere and interplanetary space (e.g., Greenwald et al., 1990).

\section{Concluding remarks}

Radar studies of the ionospheric irregularities over the Antarctic Continent have been less active in comparison with those over the Arctic. One of the reasons has been that in Antarctica it is not easy to construct a twin VHF radar system, capable of observing two-dimensional electron-drift vectors, such as the STARE and SABRE radars in Scandinavia and the BARS radar in Canada, because of difficulty in keeping radar sites at the most appropriate locations. This difficulty can be overcome by application of modern HF radars. The twin HF radar system consisting of the Syowa Station and Halley Bay radars, and other $\mathrm{HF}$ radars in Antarctica under construction or being planned, will largely contribute to the studies of the ionospheric irregularities, ionospheric physics, and ionospheremagnetosphere coupling at the southern high latitudes.

Acknowledgements. The studies using the Syowa Station VHF radars were carried out when the author was with the Communica- tions Research Laboratory, Ministry of Posts and Telecommunications. The author would like to thank the staff of National Institute of Polar Research and N. Nishitani for providing Fig. 6 in this paper. The VHF and HF radars belong to, and are operated by CRL and NIPR, respectively.

Topical Editor D. Alcaydé thanks J. P. Villain and another referee for their help in evaluating this paper.

\section{References}

Bristow, W. A., R. A. Greenwald, and J. C. Samson, Identification of high-latitude acoustic gravity wave sources using the Goose Bay HF radar, J. Geophys. Res., 99, 319-331, 1994.

Fejer, B. G., and M. C. Kelley, Ionospheric irregularities, Rev. Geophys. Space Phys., 18, 401-454, 1980.

Gorney, D. J., Solar cycle effects on the near-earth space environment, Rev. Geophys., 28, 315-336, 1990.

Greenwald, R. A., K. B. Baker, R. A. Hutchins, and C. Hanuise, An HF phased-array radar for studying small-scale structure in the high-latitude ionosphere, Radio Sci., 20, 63-79, 1985.

Greenwald, R. A., K. B. Baker, J. M. Ruohoniemi, J. R. Dudeney, M. Pinnock, N. Mattin, J. M. Leonard, and R. P. Lepping, Simultaneous conjugate observations of dynamic variations in highlatitude dayside convection due to changes in IMF $B_{y}, J$. Geophys. Res., 95, 8057-8072, 1990.

Greenwald, R. A., K. B. Baker, J. R. Dudeney, M. Pinnock, T. B. Jones, E. C. Thomas, J.-P. Villian, J.-C. Cerisier, C. Senior, C. Hanuise, R. D. Hunsucker, G. Sofko, J. Koehler, E. Nielsen, R. Pellinen, A. D. M. Walker, N. Sato, and H. Yamagishi, DARN/SuperDARN: A global view of the dynamics of highlatitude convection, Space Sci. Rev., 71, 761-796, 1995.

Haldoupis, C., A review on radio studies of auroral $E$-region ionospheric irregularities, Ann. Geophysicae, 7, 239-258, 1989.

Hasegawa, S., and I. Shiro, Spatial and temporal distribution of radar auroras over Syowa Station, Antarctica, J. Radio Res. Labs. (Japan), 17, 137-146, 1970.

Hultqvist, B., and A. Egeland, Radio aurora, Space Sci. Rev., 3, $27-78,1964$.

Igarashi, K., and S. Tsuzurahara, Spatial correlations between radio aurora and $4278 \AA$ A aurora intensity, Mem. Natl. Inst. Polar Res., Special Issue, 18, 204-211, 1981.

Igarashi, K., T. Ogawa, S. Tsuzurahara, I. Shiro, and M. Ose, Simultaneous observations of aurora with a Doppler radar and sounding rockets, Mem. Natl. Inst. Polar Res., Special Issue, 18, 391-402, 1981.

Igarashi, K., T. Ogawa, M. Ose, R. Fujii, and T. Hirasawa, A new VHF Doppler radar experiment at Syowa Station, Antarctica. Mem. Natl. Inst. Polar Res., Special Issue, 22, 258-267, 1982.

Igarashi, K., T. Ogawa, Y. Kuratani, R. Fujii, and N. Sato, $50 \mathrm{MHz}$ auroral Doppler radar observations associated with Pc5 geomagnetic pulsations, Mem. Natl. Inst. Polar Res., Special Issue, 36, 104-113, 1985.

Igarashi, K., K. Ohtaka, M. Kunitake, T. Tanaka, and T. Ogawa, Development of scanning-beam VHF auroral radar system, Proc. NIPR Symp. Upper Atmos. Phys., 8, 65-69, 1995.

Kunitake, M., T. Tanaka, K. Igarashi, S. Yamamoto, H. Maeno, and T. Ogawa, New-type echoes observed with the $50 \mathrm{MHz}$ auroral Doppler radar at Syowa Station, Proc. NIPR Symp. Upper Atmos. Phys., 6, 42-46, 1993.

Lewis, R. V., P. J. S. Williams, G. O. L. Jones, H. J. Opgenoorth, and M. A. L. Persson, The electrodynamics of a drifting auroral arc, Ann. Geophysicae, 12, 478-480, 1994.

Ogawa, T., and K. Igarashi, VHF radar observation of auroral $E$-region irregularities associated with moving-arcs, Mem. Natl. Inst. Polar Res., Special Issue, 22, 125-139, 1982.

Ogawa, T., H. Mori, S. Miyazaki, and H. Yamagishi, Electrostatic plasma instabilities in highly active aurora observed by a sounding rocket S-310JA-7, Mem. Natl. Inst. Polar Res., Special Issue, 18, 312-329, 1981. 
Ogawa, T., B. B. Balsley, W. L. Ecklund, D. A. Carter, and P. E. Johnston, Auroral radar observations at Siple Station, Antarctica, J. Atmos. Terr. Phys., 44, 529-537, 1982.

Ogawa, T., H. Yamagishi, I. Ayukawa, T. Tanaka, and K. Igarashi, Simultaneous observation of radar aurora and visible aurora over Mizuho Station, Proc. NIPR Symp. Upper Atmos. Phys., 2, 103-109, 1989a.

Ogawa, T., K. Igarashi, T. Hirasawa, M. Ejiri, and R. Fujii, HF radar experiment at Syowa Station for the study of high-latitude ionosphere: A proposal, Proc. NIPR Symp. Upper Atmos. Phys., 2, $139-140,1989 b$

Ogawa, T., A. Nomura, T. Tanaka, and K. Igarashi, Simultaneous measurements of Antarctic mesospheric gravity waves by meteor radar and lidar, J. Geomagn. Geoelectr., 41, 835-849, 1989c.

Ogawa, T., T. Hirasawa, M. Ejiri, N. Sato, H. Yamagishi, R. Fujii, and K. Igarashi, HF radar experiment at Syowa Station for the study of high-latitude ionosphere-2: A capability, Proc. NIPR Symp. Upper Atmos. Phys., 3, 91-95, 1990.

Ohtaka, K., and T. Tanaka, Long-term variations of radio auroral activity, Proc. NIPR Symp. Upper Atmos. Phys., 6, 36-41, 1993.
Russell, C. T., and R. L. McPherron, Semiannual variation of geomagnetic activity, J. Geophys. Res., 78, 92-108, 1973.

St.-Maurice, J.-P., P. Prikryl, D. W. Danskin, A. M. Hamza, G. J. Sofko, J. A. Koehler, A. Kustov, and J. Chen, On the origin of narrow non-ion-acoustic coherent radar spectra in the high latitude E region, J. Geophys. Res., 99, 6447-6474, 1994.

Tanaka, T., T. Ogawa, H. Maeno, and S. Yamamoto, Type 5 echoes observed by the VHF Doppler radar at the auroral ionosphere, Proc. NIPR Symp. Upper Atmos. Phys., 3, 86-90, 1990.

Uspensky, M. V., P. J. S. Williams, V. I. Romanov, V. G. Pivovarov, G. J. Sofko, and J. A. Koehler, Auroral radar backscatter at off-perpendicular aspect angles due to enhancement ionospheric refraction, J. Geophys. Res., 99, 17503-17509, 1994.

Waldock, J. A., T. B. Jones, and E. Nielsen, Statics of 1-m wavelength plasma irregularities and convection in the auroral E region, Radio Sci., 20, 709-717, 1985.

Watermann, J., A decade of type 3 radio aurora studies: Toward and away from the EIC interpretation, J. Geomagn. Geoelectr., 46, 285-296, 1994. 